\title{
Volumen 9
}

\section{Batllori: un ilustrado cristiano}

\author{
Cristina BarbolanI \\ (UCM)
}

La experiencia del conocimiento personal de la figura de Batllori - uno de mis recuerdos más gratos - queda asociada a los inicios de mi trayectoria investigadora, cuando participé por primera vez en un Congreso Internacional, titulado «Doce consideraciones en torno a Alfonso y Juan de Valdés» (Bolonia, 1976). No faltaban allf brillantes jovenes promesas, como Francisco Rico, pero los estudiosos entonces más conocidos habían consolidado su renombre con obras editadas a lo largo de la primera mitad del siglo XX. Los más venerados del Congreso eran, sin duda, dos insignes historiadores de idénticas iniciales: Marcel Bataillon y Miquel Batllori. Al lado de la penetrante y fina ironía «laica» de Bataillon, a Batllori le caracterizaban una gran afabilidad y sencillez, unidas a una impresionante honradez intelectual. Estas cualidades eran las mismas que yo admiraba en mi gran maestro Oreste Macrí (que también estaba presente en aquel Congreso), lo que me impuls 6 a superar la timidez debida a mi inexperiencia y a participar en la grata conversación del jesuita. Mi impresión fue que valoraba positivamente mi trabajo, a la vez que me transmitía algo de su inagotable curiosidad intelectual, animándome a continuar. Un encuentro de este tipo nunca se olvida, y de hecho recientemente lo tuve muy presente al redactar un artículo, ahora capítulo de mi libro sobre Alfieri en Espana (Modena, Mucchi 2003); y la nota de agradecimiento que alli lo evoca, escrita aún en vida de Batllori, no ha sido modificada, del todo intencionadamente por mi parte.

La lectura del volumen $\mathrm{XX}$ de su Obra Completa (La Il.lustracio) me pone ahora frente al hecho consumado de su muerte, pero también me brinda la oportunidad de acompañar al investigador y al hombre que añoramos, en un recorrido intelectual a través del siglo que, como recuerda Solervicens, constituye el tema estudiado por él con mayor asiduidad. Es una suerte que el propio Batllori haya podido seguir personalmente la organizacion de estos trabajos, que aparecen, así pues, en un orden refrendado por el autor. Esta agrupación acertadísima permite alcanzar una penetrante visión de conjunto sobre la Ilustración, observada desde la perspectiva de un jesuita historiador de la cultura que ha querido superar mitos y tópicos de uno y otro signo para encarar una realidad, a veces dura para su condición de religioso (el siglo de la llustración es el mismo de la supresión de los Jesuitas), cuyo análisis se le ofrecía, en cualquier caso, necesitado de continuos distingos y matices. A pesar de la objetividad que se exige a sí mismo como historiador, el hombre Batllori palpita en todos estos trabajos.

La sección primera (Europa al segle de les Llums) procede hacia lo particular desde lo general (1. 1. Espanya a l'Europa del segle XVIII). Empieza, pues, 
con una clarísima síntesis que tiene como centro conceptual la famosa pregunta de Masson de Morvilliers en la Encyclopédie methodique, que sitúa a España en el punto de mira de Europa en sus dos aspectos más criticados: la Inquisición y la conquista americana, ésta última ligada también a la diferente consideración del «salvaje» en la época ilustrada.

El hilo conductor de esta investigación de Batllori es el principio dinámico del «viaje», considerado en sus dos vertientes: la amena y enriquecedora, típica del libertinismo ilustrado, y la amarga, pero también enriquecedora, experiencia del destierro (emigración de los partidarios de la casa de Austria a raíz de la guerra de Sucesión, y expulsión de los Jesuitas). Circulan así los hombres y las ideas a través de una Europa en ebullición que inicia su andadura en la edad moderna, y que mira a España entre juicios y prejuicios, como el de la «doctrina climática» del que no anduvo exento el propio Voltaire.

El corpus de documentación relativo a viajes, destierros, etc. que maneja Batllori, cuantitativamente impresionante, está tratado con especial sensibilidad crítica, como pocos comparatistas están en condiciones de hacerlo, penetrando en los conceptos de historia, funcionalidad, fortuna del texto. Un ejemplo de su buen hacer es que, en la distinción entre viajes superficiales u odepóricos y aportaciones «serias» a la cultura, Batllori considera entre estas últimas los relatos de viajes de ficción, pues también, y tal vez mejor, reflejan los juicios y los tópicos, o los antitópicos, de la época.

En el surgir de las opiniones europeas de unos pueblos sobre otros, la riqueza de datos y conocimientos de Batllori le permite dedicar gran atención a las alemanas y francesas, pero su ensayo toca el tema ineludible, y para mí del máximo interés - que aparecerá en varios estudios especificos posteriores - de las relaciones hispanoitalianas, que en el momento de la Pre-ilustración (término que el jesuita utiliza mucho, en su afán de precisar) se concretaron en la adscripción a la academia romana de la Arcadia de miembros españoles, como el musicólogo Antonio Eximeno o el diplomático Nicolás de Azara.

A las relaciones culturales hispanofrancesas dedica Batllori el segundo apartado (1. 2. Les relacions culturals hispanofranceses: corrents d'investigació) que se basa en el conocimiento de 20 años de bibliografía. El paso de los años (la bibliografia llega al 1965) no ha afectado en absoluto, en mi opinión, a este estudio, pues sigue siendo un fundamento sólido donde asentar cualquier investigación: «Empezar por Batllori», habria que recomendar a cualquier doctorando en la materia. Cabe subrayar, asimismo, el rasgo de «coraje» que supone la elección del tema. No hay que olvidar, en efecto, que la revalorización del siglo XVIII espafiol, que despues de los trabajos de J. Arce y de J. Caso nos parece un hecho consumado, en su día fue poco menos que una hazaña realizada contra viento y marea, pues la Ilustración llego a ser considerada un aspecto de la "Antiespaña», como también recuerda Batllori, cuyo intento es, precisamente, el de superar todos estos mitos y antimitos («España eterna», «Antiespaña», etc.). Tras el estudio pormenorizado de las instituciones culturales, de la enseñanza religiosa y de las corrientes jansenistas y antijesuíticas presentes en la sociedad dieciochesca y en la misma iglesia, Batllori considera también a los protagonistas de la Ilustración española, 
precisando el estado de la cuestión proporcionado por los estudios existentes sobre Feij6o, Campomanes, Jovellanos, Mayans, Olavide, etc. Sobre la espinosa cuestión del papel de España en los movimientos de independencia de América latina, a saber, si influyó en ellos más la Ilustración «laica» o bien el populismo de la filosofía cristiana del siglo XVI, Batllori enumera trabajos y opiniones, pero termina declarando «Jo, personalment, m'inclino por la tesi de la Il.lustració». Un juicio ecuánime y valiente por parte de un religioso que descarta todo partidismo, una opinión libre propia de un «jesuita atípico» como se define a sí mismo en el tercer apartado de esta sección (1. 3.) titulada La declaració dels drets de l'home de 1789, texto de un discurso al Parlament de Catalunya que después no llegó a ser pronunciado. En este discurso Batllori opina sobre la condena de esta declaración de derechos humanos por parte del papa Pío VI llamándola «intromisió abusiva del poder eclesiàstic en el dret civilpolític» (pág. 106) e insiste sobre un aspecto hasta entonces relevado de modo tan sólo anecdótico, la paralela Declaración sobre los derechos de la mujer y de la ciudadana, presentada a la Asamblea en 1791 y dirigida a la reina María Antonieta por Olympe de Bourges (seudónimo de Marie Gouze) en 17 artículos. Este detalle simpático añade más rasgos de humanidad a la figura de quien asume el reto de conciliar razón y fe ahondando en ambas facetas, descartando en suma los falsos simulacros de ambas actitudes:

no és pas aquesta la primera vegada que declaro que el meu previ pas per la Facultat de Dret de la nostra Universitat, i per la de Filosofia i Lletres, m'ha fet sempre un jestita atipic, radicalment catòlic liberal, i decididament català i democràtic, sobretot durant els decennis que jo sempre titllava de pseudocatolics i d'anticristians (pág. 95).

En la sección segunda, con el significativo título de Il.lustració $i$ Església, Solervicens ha refundido y traducido al catalán varias redacciones de una reflexión de Batllori en torno a estos dos términos, aparecida en versión italiana, castellana y catalana con ligeras modificaciones. En su adhesion a las posiciones más avanzadas del Concilio Vaticano II, Batllori puede considerarse un ilustrado cristiano del siglo XX; de ahí la centralidad del problema que, a mi modo de ver, tiene algo de punctum dolens. Como historiador del XVIII se pregunta si existió una ilustración cristiana, 0 al menos un punto de encuentro entre sustantivo y adjetivo, términos que a veces parecen excluirse. Para una respuesta satisfactoria le ayuda al jesuita su conocimiento de la perspectiva europea, pues si resulta difícil acercar la Ilustración francesa al reformismo eclesiástico de la Época, no ocurre así con la Aufklärung alemana y con la figura de Kant. Su dominio de los datos y su capacidad de matizar y puntualizar a la luz de los estudios más recientes, le permiten hilar muy fino para establecer sutiles distinciones cronologicas, como la existencia, en Italia y en España, de una Pre-ilustración, representada por Muratori y Feijó, toda vez que, si nos atenemos a los hechos, para Batllori está claro que no fueron precisamente los ilustrados, sino los déspotas los que suprimieron la Compañía de Jesús. Con ello parece sugerir sutilmente que también la fórmula del «despotismo ilustrado», de uso común y general, resultaría igualmente contradictoria en sus términos, 0 tal vez aun menos aceptable. $Y$ en el área hispanoitaliana constata Batllori una actitud cultural básicamente acorde a los principios cristianos en Jovellanos, Menéndez 
Valdés, Joan Andrés, Esteban de Arteaga, Genovesi, Spedalieri, Baretti, Bettinelli...lo que, a mi entender, no puede negarse, pero supone una visión muy amplia y abierta, comprensiva, plural y no excluyente: la del «ilustrado cristiano» que fue Batllori.

En la parte tercera (Carles III de Borb6, un monarca ilustrado) el historiador se acerca con prudencia al tema vidrioso de la expulsión de los Jesuitas y a los protagonistas activos o pasivos de ese hecho crucial. Con tal finalidad revisa y precisa la historia de los manuales, estableciendo que no fue sólo la actuación de Tanucci, sino todo el ambiente jurisdiccionalista antirromano (impulsado, aunque no creado, por Giannone), lo que hizo pasar a Carlos de Borbón del galicanismo de Felipe $\mathrm{V}$ y del regalismo concordatario de Fernando VI, a un jurisdiccionalismo antipontificio más radical que le llevarfa a tomar la fatal determinación. Por otra parte no parece que en la guerra de Sucesión todos los Jesuitas hubieran sido antiborbones, y Batllori averigua que estuvieron en ambos bandos, amén de hacer justamente hincapié en la función de consejeros políticos de los confesores jesuitas, presentes en las más importantes cortes europeas. En cuanto al papel de Tanucci (3. 2), ofrece datos nuevos sacados del Archivo de Simancas sobre su valoración de los Jesuitas, reconociendo que sus criticas iban dirigidas en especial al anticuado sistema de enseñanza de la jesútica ratio studiorum. Concluye Batllori que Tanucci no fue directamente responsable de la expulsión, aunque es cierto que la aprobó con pleno convencimiento a posteriori.

Insistiendo en el tema de la expulsion y en sus motivos, en 3. 3. (Carles III a Napols i a Espanya) Batllori sigue precisando, matizando, afinando sus argumentaciones y apoyándolas firmemente. Cambiando el punto de vista, situándose a un lado y al otro del debate, se acerca a una interpretación que excluye el pensamiento ilustrado de los motivos de la expulsión. Analiza el dictamen de Campomanes con una agudeza penetrante no exenta de ironía:

El segon vici que Campomanes atribuïa als jesuites era la monarquia «despotica» de la Companyia de Jesús, que amb la seva cega obediencia no podia conviure amb un Estat modern - $t s$ a dir, que el govern absolutista dels jesuiltes no podia deixar d'entrar en conflicte amb la monarquia absoluta dels Borbons a Espanya (págs. 160-61).

La sección cuarta (Ensenyament $i$ cultura a l'drea catalana) desde la perspectiva europea nos traslada, como en un zoom, hacia el análisis de instituciones y personajes geográficamente próximos, que surgieron de estos impulsos renovadores preilustrados. Se trata de un terreno más familiar y entrañable, sea porque el tema de la ensefianza le apasiona a Batllori, sea por tratarse de estudios que en principio iban destinados a un proyecto bruscamente interrumpido, que debía llevar a cabo junto al padre Ignasi Casanovas, trágicamente asesinado en la Guerra civil española. Pese a su inevitable dispersión, los tres trabajos aquí agrupados dan fe del rigor y la constancia con que se reunieron los materiales de estudio y del escrupuloso analisis al que fueron sometidos. Sobre la real y pontificia Universidad de Cervera (4.1.), instituida por Felipe $V$ en 1714 para privilegiar la única localidad catalana que no habia tomado partido por la casa de Austria en la guerra de Sucesión, se plantea Batllori la cuestión de si esta cir- 
cunstancia hizo que la Ilustración española se vinculara a otras instituciones más que a la universidad; pero observa que esto ocurrio en toda Europa y que todos los movimientos culturales (como por ejemplo, el Renacimiento) han buscado siempre vías alternativas a las instituciones establecidas, entre las cuales la universidad constituye una de las más tradicionalmente conservadoras. No fue, así pues, ninguna excepción el centro de Cervera, conectable si acaso con una erudita Pre-ilustración y no ciertamente con la más avanzada Ilustración. Batllori sigue minuciosamente paso a paso las etapas de la evolución pedagógica de esa universidad y determina la parte que en ella tuvieron los jesuitas, que alli se hicieron cargo de las cátedras de humanidades clásicas y potenciaron considerablemente el latín, que se fue imponiendo en la disyuntiva castellano/catalán. Para Batllori el balance sobre el peso específico de la cultura de Cervera no deja de ser positivo, pero tomando buena nota de sus limitaciones (entre ellas, ¡la no abundancia de libros!), y no olvidando más importantes experiencias posteriores de muchos de los que pasaron por sus aulas, que después formarian parte de la cultura romántica de Cataluña: Manuel de Cabanyes, Manuel Milá i Fontanals, Joaquín Roca i Cornet...

A este estudio le siguen (4.2. y 4.3.) dos semblanzas de personajes ilustrados, un laico y un religioso: el valenciano Gregorio Mayans i Siscar y el mallorqui Cardenal Despuig. Del primero destaca Batllori su importante obra jurídica y su extraordinaria erudicion, comparable a la de Muratori; le considera enlace entre la cultura catalana (la familia Mayans es de origen catalán) y la valenciana (nacio en Oliva, donde en 1982 se celebro el Simposio del bicentenario, al que Batllori aportó esta contribución) y estudia a través de sus cartas la personalidad de este ilustrado; y asimismo precisa su relación con los Jesuitas, generalmente muy crítica con la Compañía, pero con numerosas excepciones en el trato privado con algunos jesuitas que le fueron amigos. En la siguiente semblanza del prelado Antoni Despuig i Dameto, que tuvo una parte muy activa en la Real Sociedad Económica de Amigos del País antes de su marcha a Roma (donde varias veces fue auditor del tribunal de la Sacra Rota y realizo una brillante carrera, hasta el cardenalato que le otorg6 Pío VII), Batllori rescata la mal llamada «historia local» a sabiendas de que forma parte de la Historia con mayúscula, si se estudia con el amor y el rigor de los que él mismo da cumplido ejemplo.

La parte quinta (Ensenyament $i$ cultura a la Italia il.lustrada) reúne tres aportaciones de gran interés. La primera (5. 1. Filippo Febei, promotor de la historia eclesidstica al col.legi romd) reproduce un texto fundamental: la Memoria sobre la creación de una nueva cátedra de Historia eclesiástica, cuidadosamente anotada, que nos introduce en ese ámbito con sus prioridades didácticas y la justificación necesaria para plantear cualquier iniciativa novedosa; la segunda realiza una instantánea de época de una institución tan emblemática como la del Colegio de España en Bolonia a finales del siglo XVIII (5. 2.), colegio entonces «mixto» (es decir, a carácter eclesiástico y laico) del que examina los distintos rectorados, y asimismo el papel que tuvo el Colegio en la acogida de los Jesuitas expulsos, que a veces resultaron activos colaboradores.

El tercer trabajo de esta sección (5. 3.) es un discurso pronunciado por Batllori en un Congreso para conmemorar el segundo centenario del Sínodo de Pistoia; sínodo promulgado por el cardenal Ricci, arzobispo de Pistoia y de Prato, 
en 1786, y posteriormente - pero no inmediatamente - condenado por el papa Pío VI. En el enfrentamiento dieciochesco jansenistas/jesuitas, aun reconociendo el trasfondo político subyacente a ambas corrientes religiosas, la honradez intelectual de Batllori no tiene inconvenientes en admitir que el jansenismo, diametralmente opuesto a los Jesuitas, representó, en algunos aspectos de renovación y reforma de la iglesia, ideas progresistas mucho más cercanas a la Ilustracion. Las posiciones avanzadas de este Sínodo dominado por la corriente jansenista anticiparon en cierto modo, según Batllori, los planteamientos que aparecerán en el Concilio Vaticano II. Una vez más, este estudio documentadísimo utiliza la erudición bibliográfica razonada, cribada, comparada, a la que Batllori nos tiene acostumbrados.

Asimismo un impresionante despliegue de conocimientos bibliográficos cierra este volumen dedicado a la Ilustración, con las partes sexta (Orientacions bibliogrdfiques) que agrupa 6 trabajos, y la séptima y última (Notes critiques) que consta de 15 reseñas. Debido a la gran variedad y amplitud de los temas tratados no es el caso de hacer una mención particular para cada aportación: una cadena de reseñas de reseñas, susceptible de continuar ad infinitum, podría resultar un ejercicio estéril de crítica. Pero sí conviene que se realce, en esta parte, el talante y la actitud de un estudioso de extraordinaria capacidad asimiladora, que saca el mayor partido de una exhaustiva información bibliográfica, seguida día a día en sus avances; el Batllori lector voraz, agradecido pero también exigente y riguroso (hay que ver jcon cuánta humildad, pero con cuánta firmeza, echa de menos a veces un (ndice de nombres!). El saber de Batllori no se encierra en torres de marfil individuales, sino que se inserta sobre las aportaciones de una comunidad investigadora de la que él se sabe parte integrante; y en el coloquio ágil con los textos aparecen sus adhesiones y sus perplejidades, sus críticas y sus sugerencias, siempre plasmadas en valiosas orientaciones de gran utilidad didáctica (de hecho algunos de los trabajos reseñados son tesis doctorales).

Como ejemplo de este talante reproduzco unas impresiones referidas en estilo coloquial en una reseña en francés, al describir la atmósfera que se respiraba en Varsovia en un Congreso de 1978 titulado Cattolicesimo e Lumi (pág. 468):

$<. .>$ tous les autres dirigeants de la section III du Congrès de Varsovia $<. .>$ ont preferé dire Aufklärung catholique et Aufklarung chrétienne, que parler de «Lumières» catholiques ou chretiennes, ou d'«Illuminismo cattolico» ou «cristiano», même dans un volume qui porte le titre : Cattolicesimo e Lumi. Cela pourrait faire penser que tous, a Varsovie, nous nous sentions mauvaise conscience, bien convaincus qu'au moins le mot français «Lumières» ne pouvait pas s'accorder avec ses deux épithètes, «chrétiennes» et «catholiques» ; et que, pour cette raison, nous devions nous refugier, tous, sous le substantif allemand Aufklarung, qui n'est pas tellement opposé frontalement à ces deux épithètes-là et qui est plus riche de connotations culturelles que religieuses.

Mais, plutot que de mauvaise conscience ou de mauvaise foi, on devrait parler d'honnêteté professionelle. Les Lumières indiquent normalement en français las positions extrèmes de l'Aufklarung, ou les actitudes critiques, rationalistes, matérialistes, athéistes ou du moins déistes l'emportent, au sommet des intellectuels - les philosophes - et des sociétés läques qui constituaient la socié- 
té. C'est pourquoi on avait tendu, spontanément, à écarter le mot «Lumières» -et aussi celui de «Lumi» en italien - pour arriver, ici, au maximum et peu souvent, a killuminismo cristiano», écrit -je ne sais pas si c'est intentionnellement - en minuscules.

Valía la pena, desde luego, reproducir esta cita algo extensa porque, en mi opinión, resume la inquietud intelectual y cierto estado anímico de Batllori que subyacen a casi todas las investigaciones publicadas en este volumen, aunque se concentren especialmente en el significativo título de la sección 2, es decir Un problema central: Il.lustració $i$ Església, ya comentado.

Si se me permite una reflexión personalísima, es posible que Batllori haya estudiado tan intensamente el siglo XVIII y la Ilustración porque se negara a admitir toda presunta incompatibilidad entre razón y fe. Como el gran escritor italiano Alessandro Manzoni, apostó por la vía difícil de un cristianismo «pensante», del que nos dejo un gran ejemplo en su buen hacer y en su apertura intelectual. 